\title{
Giving children voice in the design of technology for education in the developing world
}

\author{
Helene Gelderblom \\ Department of Informatics, University of Pretoria, South Africa
}

\begin{abstract}
Of the numerous projects that involve ICTs to solve the problems of the developing world, many are unsuccessful. Reasons reported in the literature include lack of attention to how the human and social systems need to adapt to the new technologies, problems with the intent of the initiators, and lack of user involvement. Focusing on the design of ICT for education and acknowledging the range of complex reasons for possible failure, this article focuses on the lack of involvement of end users (specifically children) in the design and development of ICT solutions. Children in the developing world are not given voice when it comes to the design of technology aimed at providing them with better education. Through examination of the concept of "children's voice" as well as through discussion of a practical design case to support underprivileged children in South Africa, this article shows that

1. listening to children requires that adult co-designers have the correct attitude towards their child partners and that they are committed to really hearing them

2. power relations and context play an important role in the contribution children can make,

3. South African children have the ability to provide essential input into the design of technology for education.

The exploration of disciplines such as youth development, the cultural politics of education and childhood studies alongside ICT for development, provides an enriched view on the role of participatory design in the latter field.
\end{abstract}

KEYWORDS: Participatory design, children's voice, ICT for education

CATEGORIES: K.3.1, H.1.2, H.5.3

\section{INTRODUCTION}

Over the past decade there has been a lot of emphasis on the use of information technology to solve problems in the developing world. Unfortunately these projects are not always as successful as those who invest in them envisioned, mainly due to a lack of attention to how the human and social systems within which they are supposed to be used need to adapt to the new technologies [1] 2.

Various examples of failed ICT system can be found in the literature [3] 44 5]. Brewer et al. 3] discuss their experience in trying to deploy technology-based systems in rural India. Despite thinking that they had paid careful attention to needs assessment and user interface design in the development of the Simputer ${ }^{1}$ the system failed. The regional and cultural characteristics of the actual users did not match their user model. Brewer et al. learnt through experience that:

effective codesign requires using local

knowledge to understand the appropriateness

of certain technologies over others [3, p. 35]

It is, however, not only the lack of user understanding

Email: Helene Gelderblom helene.gelderblom@up.ac.za

\footnotetext{
${ }^{1}$ http://www.simputer.org
}

and involvement that leads to failure. Political and business issues can also get in the way. Chetty and Grinter 4] designed and implemented a telemedicine communication system in rural South Africa that allowed nurses to communicate through a wireless network with doctors via voice, text and image data. During the testing phase they were forced to terminate the project and retract their system because a semi-private organisation with the necessary influence wanted to deploy their own telemedicine system in that area.

HCI for development (HCI4D) is a sub-field of HCI that is particularly concerned with addressing problems of designing for development. Irani et al. 6] explains that HCI4D is not as new a field as the HCI community generally believes. According to these authors the 'Appropriate Technology' (AT) movement in the 1970 s and 1980 s was a reaction to failures of technology transfer from industrialised to other contexts. These failures were ascribed to differences in infrastructure or to incorrect social, cultural, political, or economic assumptions. Then already the AT approach encouraged the development of smaller technologies that focus on local needs.

Irani et al. 6 raise the following issues that, if not handled correctly, can lead to failure of ICTs for development: 
- Thinking in terms of global, technical solutions to problems

- Aligning development projects with the interests of commercial organisations in developed countries

- Monetary flows in the wrong direction

- Disempowerment through consumer-oriented development

Developing ICTs in a context where these factors are evident, often leads to 'solutions' for which problems and users need to be identified after the fact.

Various large scale projects aimed specifically at solving problems with education in the developing world have been deployed or are in the process of being implemented. Some of these have led to improved learning [3] and some were less successful.

The most well-known example is the One Laptop Per Child (OLPC) project, through which children across the world would be provided with a $\$ 100$ laptop preloaded with educational content $[5]$. Despite strong support from governments and industry partners, the project failed in many countries. Kraemer says:

OLPC created a novel technology, the XO

laptop, developed with close attention to the needs of students in poor rural areas. Yet it failed to anticipate the social and institutional problems that could arise in trying to diffuse that innovation in the developingcountry context. [5, p. 66].

OLPC is a clear example of a thoughtfully planned solution that failed in terms of adoption, mainly because of the complexity of, and unfamiliarity with, the social and cultural environment where it was deployed [5] 7 . An additional problem was that the price of the XO laptop never dropped to $\$ 100$ and manufacturers such as Acer and HP launched low cost netbooks that were in direct competition with it.

In countries where OLPC succeeded, such as Ethiopia and Uruguay, evaluation studies report that there was improved availability of learning material via the laptop, but even there the project is not running without problems. Faulty input devices, connectivity problems, software that does not always work and lack of teacher training are mentioned as some of the problems [5]. ICT solutions exist in an ecosystem that includes hardware, software and infrastructure that all require services such as installation, training and technical support on a long term basis. These resources are scarce in most developing countries 5 .

I acknowledge that there are a range of complex reasons for failure and lack of adoption of ICT systems developed for education. In this article, however, I highlight two reasons, namely:

1. Lack of involvement of end users in the conceptualisation, design and development of the solutions: although many of these systems are intended for use by children, there is no evidence that children are consulted in the planning, design and development (see Section 2 below).

2. Following a top-down approach rather than a bottom-up approach in the life cycle of these solutions: governments, research institutions and pri- vate organisations come up with grandiose ideas on how to incorporate ICT into the education system and invest large amounts of funds on large scale, long term projects. Following such an approach (rather than a stepwise, bottom-up approach where smaller solutions are first tested and then expanded if successful) leaves little room for proper testing of ideas before they are implemented.

These practices create a situation where children in the developing world are not given a voice when it comes to the design of technology aimed at providing them with better education. I argue that this is detrimental to the sustainability of the proposed solutions.

Through examination of the concept of 'children's voice' as well as through practical experience in codesigning, with children, a small-scale technology solution to support underprivileged children in South Africa, I show that really listening to children requires that adult co-designers have an appropriate attitude towards their child partners and that they are committed to really hearing them. I also show how the context influences the contribution children can make and how this should be addressed when designing with children.

Through consultation of research reports on codesigning technology with children and related literature from the fields of youth development and childhood studies, I unpack the above problems and contributions, ending with some guidelines for designing ICT for development solutions with child partners.

\section{THE ABSENCE OF CHILDREN'S VOICE IN ICT FOR DEVELOPMENT}

Through institutionalised processes such as those aimed at protecting vulnerable children during the research process, children have been excluded from participation in the creation of knowledge about themselves. Coppock believes that this protectionism 'disguises a fundamental mistrust in children's competence' [8. p. 438].

Disciplines such as social work, anthropology, sociology and health studies have, over the past two decades, given much attention to the concept of 'children's voice' and how children can contribute in research and policy development. Whereas 20 years ago it was almost unheard of to consult with children in search of solutions to real world problems, the 'new sociology of childhood' movement and recent children's rights acts have brought about an awareness that children need to be included in research and discussions about problems that affect them, and that their contributions should not be assumed to be untrustworthy or idiosyncratic 8. Graham and Fitzgerald 9] are of the opinion that children's participation has become a given in studies about policy and social programmes that relate to children.

In her research with children as peer researchers, Coppock 8 worked from three assumptions: that childhood is a social and not a biological construction, that 
children are worthy of being studied from their own perspectives, and that an ethnographic approach to social research is better suited for child-centred research than a positivist approach. Together these assumptions support the idea that children can generate knowledge, receive knowledge and be the objects of knowledge.

The literature on social issues such as childhood and politics of education refers to three rationales for including children when doing research that affects them 9] [10: the enlightenment rationale, the empowerment rationale and the citizenship rationale. These are elaborated in Section 3.1 below.

The problem is then: If other disciplines are so receptive to the idea of including children in research about things that have a direct impact on their lives, why do we not see more involvement of children in the design of ICT for development, and specifically in the design of ICT for education?

Referring to the work of Castells, Mallan et al. 11. explain how children born into a network society have knowledge of, and experience with, technological spaces that are very different from how adults experience these. Their more natural relationship with technology gives children an advantage over adults when confronted with a technology design task. In the fields of humancomputer interaction and interaction design, the past ten years have seen an explosion of interest in involving children in the design of technology aimed at child users. Various intergenerational design groups have been established and many successful technologies have been developed with the help of children. For example, Kidsteam at the University of Maryland is a design team that uses the cooperative inquiry method of design partnering [12]. In this team, children aged from 7 to 11 participate as partners in regular design projects to design new technologies aimed at children. Many successful designs have emerged from their work, for example the International Children's Digital Library ${ }^{2}$ StoryKit [13], and the Nick App ${ }^{3}$

Such groups and their design products have predominantly appeared in the developed world where they function within a context of access to technology resources that far exceeds what is available to children in the developing world.

I could find no examples of design tasks that involved South African children. Mills-Tettey et al. [14] report on a study conducted in Ghana and Zambia to evaluate a computer-based reading tutor. In that study the children were just observed. The evaluators communicated primarily with teachers at the schools and centres where the software was installed on computers that the children had access to.

In reports on the OLPC project's deployment in African countries there is no evidence of involvement of children in the design of the content that was made available on the OX laptops. The needs associated with the developing context that were addressed in the design of the laptop were focused on the physical design of the laptop (e.g., robust, dirt proof, affordable)

\footnotetext{
${ }^{2}$ http://en.childrenslibrary.org

${ }^{3}$ http://www.nick.com/app
}

[5] rather than on the content that the children would engage with.

Ogan et al. [1] confirm the impression that very few user studies have been conducted with children outside of the developed world. They explain why successful applications designed in a developed context will not necessarily succeed in a developing environment: besides obvious issues with the content, such as the language used, there may be more subtle cultural differences that have to do with teaching practices and the way that students access and interact with educational software [1]. Access to resources (or lack thereof) affects how technology is used.

This all lines up with the postcolonial view on interaction design [6]. Postcolonial computing is about understanding how all design research and practice is culturally located and how it always involves issues of power and authority. It is not merely an approach to provide better design for those who do not have it [6].

In following a postcolonial approach to HCI for development, the emphasis moves from user-centred design to community-centric design. Engaging with the community for whom the design solution is aimed is regarded as essential for requirements elicitation and codesign and it will improve the sustainability of systems once deployed 6]. This implies that when designing ICT for education, not only should we involve children in the design, but we should engage with children in the specific communities where they will eventually use the design.

Creating opportunities for children to become involved in the design of real-world technology solutions is not easy: like adult designers, child designers have to acquire design skills and domain knowledge before they can make a useful contribution [15]. This may take time. Adult facilitators need to have a good understanding of how to co-design with children. The difficulties could be aggravated by circumstances in a developing context: whereas children in general may be disempowered by adult-child power relations, this is more pronounced for children who are disadvantaged by their socio-economic circumstances. In a cultural context where children are 'seen and not heard', adult design partners are likely to come with preconceived ideas that may hinder young partners from voicing their ideas and needs. Language and other cultural barriers may distort their voice.

Looking at some major initiatives to introduce ICT in the development of systems providing disadvantaged children with better education, it is clear that there was very little consultation with children.

In the remainder of this article I investigate this problem by:

1. Providing evidence from the literature that children have a contribution to make (Section 3.1)

2. Discussing the role of power relations and context on children's voice as described in the literature on children's voice (Section 3.2 and 3.3.

3. Questioning the suitability of traditional design methods (Section 4.2) and proposing mechanisms to provide children in the developing world with 
voice in design (Section 4.3 and 4.4

\section{EXISTING RESEARCH ON CHILDREN'S VOICE}

In this section I consider key aspects of children's voice in participatory research as discussed in the literature.

\subsection{Why should children be heard?}

Referring to education reform, Cook-Sather [16] says we

must seriously question the assumption that we know more than the young people of today about how they learn or what they need to learn in preparation for the decades ahead. [16, p. 3].

He believes that learners should be given the authority to critique education and participate in its reform.

A good reason to include children in the design of technology which they will use is that in the context of social media and technology, children develop a vocabulary that is often not known to adults. Designing systems for them that reflect adults' ignorance in this regard may alienate children and prevent them from adopting the system. This relates to Mallan et al.'s 11 experience in participatory research with children to investigate how young people construct their own identities and social relationships in the context of technology use. Assuming that the children in their study could be described as 'tech savvy', they used this term often in their research. The participants were resistant to accept this as a term that describes them (with $60 \%$ saying that they do not see themselves as 'tech savvy'). Mallan et al. interpreted this reaction as the children's 'refusal to see themselves in adult society's terms' [11, p. 266].

Researchers continue to use their familiar, structured methods when doing research with children, although this may not be suitable in the modern context where children's lives are split between online and offline spaces and experiences 11. Mallan et al. 11 believe that in designing technology we need to draw on young people's technological skills and that they can play an important role in the development of technology-based tools. A self-acknowledged shortcoming of these authors' research [11] was that they did not ask advice from their young participants on the design of an online communication space. Ignoring the popularity of existing social networking platforms they created a new, dedicated web site that failed. When investigating new developments (such as online social networking), researchers should use exactly those mechanism in their research and not rely on traditional methodologies 11.

Mannion [10] discusses three rationales for including children in research about issues that may affect them:

1. The enlightenment rationale implies that children have something important to tell adults that may influence the decisions adults make for children.
2. The empowerment rationale, which focuses on children's rights and regards them as complete citizens with rights and responsibilities comparable to those of adults.

3. The citizenship rationale, which promotes the idea that through participation in civic activities, children will develop a sense of responsibility and a social conscience.

There may be tension between these rationales and the interplay between them can lead to ambiguity 9 . In relation to the first, we should remember that knowledge is relational and therefore, that to accept children's input as the essential truth could be misleading 8]. Although Coppock makes a strong argument that giving children a voice is a 'project of emancipation' 8, she promotes child-adult alliances in research. Children do have expertise about their own lives, but adults have a different kind of expertise about children's lives, so neither of their contributions should be considered in isolation [8].

According to Christensen [17, we should listen to children not only to see the world from their perspectives, but to acknowledge that they have the right to say what they think. We also need to be respectful of their silences, because withholding an opinion may also have meaning in the research context.

\subsection{Power relations and children's voice}

The adult-child power relationship is intrinsic in the research problem addressed in this article, namely how to provide children with a voice in design. It implies that I as a designer (like other researchers cited in the article) am in a position (of power) to provide children with a voice, should I want to and know how to. Similarly, stringent ethical clearance procedures when doing research that involves children imply inherent power relations. These mechanisms to protect children from possible harm demonstrate the underlying assumption that children are incompetent and their research encounters should be controlled by adults 8 .

Discourses about children's development describe children as being in the process of becoming complete humans 8]. Through stages of development, they gradually progress from 'incapable' children to become 'capable' adults. Coppock explains how these theories about child development have been developed by white, adult, male researchers and that the interests and concerns of children were only regarded as important in terms of their functional relationship to the concerns of adults.

However, we cannot just move from the view that children are incompetent to the opposite view that they are competent [18. Komulainen believes that children can simultaneously be both and that where they are between these extremes depends on adults. Requiring children to speak up may be intrusive and cause distress 18. We therefore do need to think carefully about when and how we involve them so as not to cause them harm. 
In doing participatory research with children, Mannion learnt that

the children's places and voices and participation are not 'stand-alones'. They are tied up with the attitudes, empowerment and participation of adults. Conversely, however, adult participation is affected by their own childhood experiences, by prevailing constructions of children/childhood, and adults/adulthood, and by the agency of children today. [10, p. 413]

Because young children tend to accept their inferior position, they are very likely, in a participatory research context, to accept the language and actions of the adult researchers. This means they might just be acting out the perceptions that adults have of them [11. There is a danger that adult partners could miss this and assume that they are hearing children's voices when they are actually just hearing reflections of their own.

When we as researchers explicitly ask children to explain their needs, views and opinions, we are not only inviting them to participate, we are also committing ourselves to acknowledge that the children have a viewpoint that is worth listening to, that should be clarified and that should be responded to 9 . An adult's general view of children will necessarily influence relationships in the context of participatory research. Individual researchers may learn to adjust their views and accept children's input, but real emancipation of children will require addressing the general power relations that are culturally [17], socially, politically and economically [8] informed.

The decision to involve children and listen to them is just a starting point [10. To really understand their input we need to acknowledge how the research environment we create for listening to them and the spaces they generally live in, are created through the actions of adults. Child-adult relations and the environment created by adults for children have a direct impact on which children we listen to, what they can speak about and what effect their opinions will have. The role of context is explored further in the next section.

\subsection{The influence of context on children's voice}

Referring to the work of Christensen [17, Hill [19] says:

Evidence has shown that children are highly sensitive to the context in which research takes place. Children interpret what adults say to them and respond to questions according to expectations about what they think is expected of them, influenced by their perceptions of the micro-environment in which research takes place. [19, p. 82]

For example, if participatory research is conducted within a school setting, children's behaviour will necessarily be affected by the rules and customs that apply at the school, even if the researchers are not associated with the school [19].
Conducting research in a familiar setting can also have a positive effect on participatory research. Researchers should consider whether the research practices reflect the children's experiences, interests, values and everyday routines, and that they should familiarise themselves with the ways in which children express and represent these aspects of their lives [17. They should thus create spaces that are familiar to their child partners and allow children to be themselves.

Komulainen describes children's 'voice' as a multidimensional social construction that can change according to the 'discourses, practices and contexts in which they occur' [18, p. 13]. Taking a slightly negative stance, Mannion 10 warns that children's voices can easily be distorted by cultural and other factors. It is important that researchers acknowledge these contextual influences so that they understand when they have really communicated with their child partners and when they have failed.

The discussions in Sections 3.13 .3 demonstrate that researchers who engage with children in the research process need to reflect on their own, established views of children, they need to understand the relations with children and how these play out in the research context, and they should acknowledge the effect that the broader social context as well as the immediate research spaces may have on children's contribution. In the next section I link these issues to the problem addressed in this article with reference to a practical design case.

\section{PROPOSED MECHANISMS FOR GIVING CHILDREN VOICE}

In this section I present my ideas on how to solve the problem of providing children in the developing world with a voice in design. That is, how we can give children, and specifically children from underprivileged communities, opportunities to provide input into the design of technology that may help to improve their education.

\subsection{How this research was conducted}

The question addressed here is: How can we give children voice in the design of ICT for education in a developing in environment?

To answer this I firstly needed to confirm that children are generally not consulted in such design projects and the reasons for that, and secondly, whether it is at all viable to make the effort to involve them as partners in design. This was done through an investigation of the literature. Andersson and Hatakka 20 call on ICT for development researchers to consult development disciplines outside Information Systems when we situate our work or develop new theory. My literature investigation relied heavily on research reports from youth development, the cultural politics of education and childhood studies.

As reported in Section 1, a thorough literature search yielded no examples of ICT4D design projects 
where children were equal partners in design. The literature reviewed in Section 2 gives further evidence that children are excluded from ICT design projects and provides possible reasons why they are excluded. Section 3 provides evidence from the literature that children should be given voice in research that affects them and addresses two main obstacles, namely power relations and context.

Having confirmed the absence of children's voice in design and the need for their participation, the next step is to determine whether existing participatory design methods are adequate for providing children with voice. Referring to the obstacles identified in the literature investigation, Section 4.2 below explains the shortcomings of these methods and how Irani et al.'s postcolonial approach [6] can be used to adapt the traditional design process to address the shortcomings.

The final step in the research is to articulate the mechanisms for giving children voice in design and applying them to a real-world design case. In Section 4.3 I briefly describe the design case. In Section $4.4 \mathrm{I}$ discuss specific aspects of the case that call for adapting traditional design methods and then, using Irani et al.'s framework as guide, I provide a detailed discussion of four mechanisms for giving children voice. I justify these with reference to their application in the design case.

\subsection{Where existing design methods fall short}

From an interaction design perspective, the solution may seem obvious: conduct participatory design (or cooperative inquiry) sessions with children where they are presented with the problem to be solved and ask them to come up with solutions and prototypes. Cooperative inquiry 12 has proven successful and there are a range of design techniques that can be employed to provide children with opportunities to contribute. Designers can take from the child partners some 'big ideas' and develop these into workable solutions. Following this approach in a developing context will already be a big improvement on current practice in ICT for development, but it may fall short in some respects.

Traditional design processes follow a series of activities starting with the identification of potential user communities, the analysis of their needs, activities or behaviour, then formulating design requirements, ideation, prototyping and iteration through these activities until a design solution is articulated [6]. In Section 3.1 I referred to Mallan et al.'s 11 work that indicates reasons why such traditional approaches may not reflect children's preferences in participatory research (and hence also not in participatory design).

Irani et al. 6] suggest a different formulation of the design process that involves three components, namely engagement, articulation, and translation. Engagement refers to immersion into an application domain or connecting with users so that a real understanding of their context and behaviour can be acquired. Articulation involves the interpretation of properties of the application domain and activities that occur within the domain so that they can be formulated as requirements.
Finally, through translation, these requirements are transformed to descriptions of technology or actual technology that will support users in the application domain. Through these processes, relevant issues of power, politics and history are acknowledged in design.

I use a specific design case to show how the engagement, articulation and translation processes provide a way to organise the design process in a way that supports the effort to give children voice. A description of the design case follows.

\subsection{Example case: Designing a social-media-based cross-age tutoring system}

Two of the numerous problems with education in South Africa are very low literacy and numeracy levels. These problems develop in the early grades when children are expected to start learning the skills of reading and doing mathematics. There are a variety of reasons for this, including a shortage of properly trained teachers (especially in the rural areas), insufficient basic resources such as water, electricity, proper school buildings, and a lack of after-school learning support due to low literacy levels of caregivers or just absence of adults that are available to help. These problems cannot all be solved simultaneously and our aim is to take one of these problems - no homework supportand find a technology-based solution that may reduce the problem.

The broad idea is to create a platform whereby teenagers from privileged communities in South Africa will provide online homework support to young children from disadvantaged communities using mobile or other technology.

The primary point of departure was that we would rely heavily on children to tell us how this system should work. Both teenagers from privileged environments and young children from underprivileged communities would act as co-designers. The plan for doing this is presented in Table 1, with an indication of the current progress in the last column. We also indicate how the phases of engagement, articulation and translation relate to the steps.

\subsection{Adapting traditional methods to the developing context}

Now, to return to the reasons why the general cooperative inquiry techniques as developed by Druin et al. 12] need to be augmented:

- Of the 14 children (eight teenagers, six young children) in the design team, only one of the teenagers had any previous design experience.

- In the South African context, many children are raised and educated within a culture of strict discipline. They are expected to show respect toward adults by keeping quiet rather than challenging them or putting forward ideas when not specifically asked. 
Table 1: Design plan for the cross-age tutoring system

\begin{tabular}{|c|c|c|}
\hline & Step & Status \& comments \\
\hline \multirow{4}{*}{ 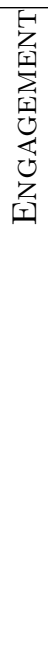 } & $\begin{array}{l}\text { Conduct interviews with teenagers from } \\
\text { privileged communities to establish } \\
\text { whether the idea is viable. }\end{array}$ & $\begin{array}{l}\text { Completed and results published in }[21 . \text { The results } \\
\text { show that teenagers will be willing to participate in such } \\
\text { a project with no tangible rewards. }\end{array}$ \\
\hline & $\begin{array}{l}\text { Identify a community of underprivileged } \\
\text { children where there is a need for homework } \\
\text { support and where we would find young } \\
\text { design partners. }\end{array}$ & $\begin{array}{l}\text { A children's home (orphanage) would provide a suitable } \\
\text { environment for the initial stages of design. A privately } \\
\text { run home in Pretoria agreed to participate and allowed } \\
\text { us to team up with their grade } 3 \text { and } 4 \text { children. }\end{array}$ \\
\hline & $\begin{array}{l}\text { Recruit teenage volunteers from privileged } \\
\text { communities to join the design team. }\end{array}$ & $\begin{array}{l}\text { Eight girls aged from } 14 \text { to } 17 \text { were recruited as tutors } \\
\text { and design partners. They attend three different high } \\
\text { schools in affluent communities in Pretoria. }\end{array}$ \\
\hline & $\begin{array}{l}\text { For one month, take the teenagers to the } \\
\text { children's home to provide face-to-face } \\
\text { homework support for the young partners } \\
\text { to immerse them in the design context. }\end{array}$ & $\begin{array}{l}\text { Completed in September } 2013 \text {. Depending on their avail- } \\
\text { ability, anything from } 1 \text { to } 6 \text { tutors were transported } \\
\text { to the home } 3 \text { afternoons a week. The children created } \\
\text { private audio recordings after the sessions to reflect on } \\
\text { their experience. These were used as data to inform the } \\
\text { design. }\end{array}$ \\
\hline \multirow[t]{2}{*}{ 范 } & $\begin{array}{l}\text { Conduct co-design sessions with the } \\
\text { teenage partners and with the young part- } \\
\text { ners respectively, where they provide input } \\
\text { into the design of the proposed system. }\end{array}$ & $\begin{array}{l}\text { Completed in October 2013: one session with the } \\
\text { teenagers and one with the young partners (and three } \\
\text { teenage facilitators). These sessions provided us with } \\
\text { low-fidelity paper prototypes developed in groups as well } \\
\text { as recordings of their descriptions of the prototypes. }\end{array}$ \\
\hline & $\begin{array}{l}\text { Analyse the design data from the design } \\
\text { sessions, build a prototype and return to } \\
\text { partners for feedback and refinement. }\end{array}$ & $\begin{array}{l}\text { In process. This will be a cyclic process until the design } \\
\text { is ready for implementation. }\end{array}$ \\
\hline 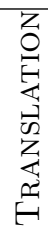 & $\begin{array}{l}\text { Develop the solution, implement it in a } \\
\text { pilot environment, test, refine, test, refine } \\
\ldots \text { and finally deploy the resulting system } \\
\text { more widely. }\end{array}$ & $\begin{array}{l}\text { This will be done from the second half of } 2014 \text {, first at } \\
\text { the Pretoria based children's home and then at the rural } \\
\text { branch of the same home. }\end{array}$ \\
\hline
\end{tabular}

- The partners who represented the disadvantaged end-users of the tutoring system had limited or no exposure to new forms of technology. This could influence their ability to conceptualise technology based solutions.

- These younger partners live in a children's home (orphanage) and are thus vulnerable and further disempowered by this particular circumstance. It therefore required a special effort to convince them that we are really interested in their ideas and take their opinions seriously.

To address these issues within the framework of engagement-articulation-translation, four guidelines or mechanisms were identified for giving children voice in the design in a developing context. I discuss them with reference to their application to the design case.

Make the real-world problem to be solved small enough so that children would be able to relate to the problem. Instead of phrasing the problem as: 'How can we address the problems with mathematics and literacy education in South Africa?', we asked 'How can we create a system whereby children who do not have homework support can get access to such support from teenagers using technology?'.

This is essential for the engagement phase, because for designers to come up with useful design solutions they must have a clear understanding of the problem domain. In Section 3.3 I referred to Christensen's [17] call for researchers (and hence, designers) to be sensitive about the ways in which children express or represent their experiences, interests, values and everyday routines. When co-designing with children, the design problem should be presented in a way that relates to these representations.

Make sure the child partners understand what we expected from them. For a month we immersed the children into a context where they received or provided face-to-face homework support, so that when asked to provide ideas as to how to do this through technology, they would have a clear mental model of the envisaged situation. Engagement specifically refers to this kind of immersion into an application domain to obtain a real understanding of the relevant context and behaviour.

Our young participants' lack of exposure to technology is similar to Chetty and Grinter's [4] experience when co-designing a telemedicine communication system with rural participants. The technological aspects (e.g., social networking applications and video conferencing) of our design task needed more explaining. 
We created opportunities for the young partners to use different kinds of technology that would be relevant to the design task. For example, we let them engage in Skype discussions with an American research partner so that they could experience the immediacy of the interaction even across vast distances and different time zones. We also allowed some time for them to freely play games on iPads and smart phones to get exposure to different sized screens and to touch screen interaction.

Let the young partners communicate their ideas through channels that will sidestep the strict power relations that might inhibit them if they were to communicate directly with adult partners. We let them communicate their ideas through the teenagers and through individual audio recorded stories. The young partners living in the children's home are treated with compassion, love and respect by the care givers and it is obvious that they have a very good relationship. It is understandable, however, that there are strict rules to encourage good behaviour and we observed a very clear acceptance and respect for authority from the young children. In order to encourage them to speak out the adult researchers stayed on the periphery and allowed the teenagers to take responsibility for organising the faceto-face sessions, to decide how to pair up individual young partners with teenagers and what to do during the face-to-face sessions. The teenagers also demonstrated the audio recording equipment for recording their reflections after each tutoring session. This practice supported the articulation phase, creating a space where the children felt comfortable to describe their experiences during the tutoring session and expressing opinions on what worked and what did not, what they liked and what they would change.

Give them different opportunities to provide input to cater for different preferences with regard to communicating ideas. In support of articulation we provided the following mechanisms for the children to provide input into the design:

- Private audio recordings of reflections after each face-to-face session. This was voluntary and we were not prescriptive about what they should convey or how long the recordings should be.

- In design sessions children were divided into small groups and they could work together in those groups or individually to come up with design ideas. A range of material was provided, including large sheets of paper, carbon paper, glue, coloured paper, pens, crayons, stickers, pipe cleaners, et cetera. They could just provide us with their designs on paper or in the form of low fidelity prototypes. We also invited them to present their designs to us verbally, but only if they felt comfortable doing so.

- During the design sessions with the younger children the adults were again on the side lines with the teenagers doing all the facilitation.
At the time of writing we are still in the translation phase of the project. Once the specifications have been derived from the design data we will return to our design partners to present these and get their feedback before we implement the prototype of the system. A cyclic process of testing and refining will then be conducted with the design partners as our pilot users. They will continue as design partners until the final system has been deployed.

\section{CONCLUSIONS AND FUTURE WORK}

Following Andersson and Hatakka's 20. call, in this article I borrowed from youth development, the cultural politics of education and childhood studies to explore children's voice in design and development. This has led to insights into the effect of power relations and context when engaging in participatory design with children in developing communities.

The focus was on explaining the importance of children's voice in the context of designing ICT for education. I demonstrated that traditional approaches to co-designing with children-specifically, cooperative inquiry - as it is generally used in the developed world, need some adjustment when applied in the developing context.

More pronounced power relations, increased disempowerment brought about by unfavourable social and socio-economic circumstances, and lack of exposure to technology are some of the important reasons for questioning the appropriateness of traditional methods for the developing world. Irani et al.'s [6] process of engagement-articulation-translation was identified as an approach that would allow designers to get the advantage of children's voice in design in ICTs for development.

Power relations and context emerged as primary influencing factors in the success of providing children with voice. Really listening to children requires that adult co-designers:

- Partner with real users from actual user communities in the design process.

- Acknowledge that children have an important contribution to make, even if they lack design expertise or exposure to the kind of technology that needs to be designed.

- Convey to child partners their willingness to listen and respond, and provide mechanisms that will encourage them to provide their ideas and opinions.

- Create spaces for co-design that invite contributions from children and where culturally or socially enforced power relations are flattened out.

- Critically evaluate their own views of children and the power relations that are subconsciously applied.

- Acknowledge that being born in a network society give children an advantage over adults when designing new technology solutions.

Through practical experience in designing a social media based cross-age tutoring system with teenagers 
from privileged communities and young partners from a disadvantaged community, I have seen that South African children (even those who have had little exposure to technology and live in a community with few privileges) have the ability to provide essential input into the design of technology for education.

Another issue raised in the introduction to this paper is the fact that large scale ICT for development projects often fail. I proposed that a lack of user involvement and the top-down approach are possible reasons for this. The tutoring system described in Section 4.3 is a small scale project that has the potential to grow into a widely deployed system that will benefit many young children. This system has been designed with extensive input from the end users and will be tested and refined with their help until completion. In future I hope to provide evidence through this project that a small-scale start with involvement of real child users in the design process will lead to large scale success.

\section{REFERENCES}

[1] A. Ogan, E. Walker, R. S. Baker, G. Rebolledo Mendez, M. Jimenez Castro, T. Laurentino and A. de Carvalho. "Collaboration in cognitive tutor use in Latin America: Field study and design recommendations". In Proceedings of the SIGCHI Conference on Human Factors in Computing Systems, pp. 1381-1390. ACM, 2012.

[2] K. Toyama. "On turbocharged, heat-seeking, robotic fishing poles". Communications of the ACM, vol. 54, no. 12 , pp. 29-31, 2011.

[3] E. Brewer, M. Demmer, B. Du, M. Ho, M. Kam, S. Nedevschi, J. Pal, R. Patra, S. Surana and K. Fall. "The case for technology in developing regions". Computer, vol. 38, no. 6, pp. 25-38, 2005.

[4] M. Chetty and R. E. Grinter. "HCI4D: HCI challenges in the global south". In CHI'07 Extended Abstracts on Human Factors in Computing Systems, pp. 2327-2332. ACM, 2007.

[5] K. L. Kraemer, J. Dedrick and P. Sharma. "One laptop per child: Vision vs. reality". Communications of the ACM, vol. 52, no. 6, pp. 66-73, 2009.

[6] L. Irani, J. Vertesi, P. Dourish, K. Philip and R. E. Grinter. "Postcolonial computing: A lens on design and development". In Proceedings of the SIGCHI Conference on Human Factors in Computing Systems, pp. 1311-1320. ACM, 2010.

[7] S. Merritt and S. Bardzell. "Postcolonial language and culture theory for HCI4D". In CHI'11 Extended Abstracts on Human Factors in Computing Systems, pp. 1675-1680. ACM, 2011.

[8] V. Coppock. "Children as peer researchers: Reflections on a journey of mutual discovery". Children $\& 5$ Society, vol. 25 , no. 6 , pp. 435-446, 2011.

[9] A. Graham and R. Fitzgerald. "Progressing children's participation: Exploring the potential of a dialogical turn". Childhood, vol. 17, no. 3, pp. 343-359, 2010.

[10] G. Mannion. "Going spatial, going relational: Why "listening to children" and children's participation needs reframing". Discourse: studies in the cultural politics of education, vol. 28, no. 3, pp. 405-420, 2007.
[11] K. M. Mallan, P. Singh and N. Giardina. "The challenges of participatory research with 'tech-savvy' youth". Journal of Youth Studies, vol. 13, no. 2, pp. 255-272, 2010.

[12] A. Druin. "The role of children in the design of new technology". Behaviour and information technology, vol. 21, no. 1, pp. 1-25, 2002.

[13] E. Bonsignore, A. J. Quinn, A. Druin and B. B. Bederson. "Sharing stories 'in the wild': A mobile storytelling case study using StoryKit". ACM Transactions on Computer-Human Interaction (TOCHI), vol. 20, no. 3, p. 18, 2013.

[14] G. A. Mills-Tettey, J. Mostow, M. B. Dias, T. M. Sweet, S. M. Belousov, M. F. Dias and H. Gong. "Improving child literacy in Africa: Experiments with an automated reading tutor". In Information and Communication Technologies and Development (ICTD), 2009 International Conference on, pp. 129-138. IEEE, 2009.

[15] J. Yip, T. Clegg, E. Bonsignore, H. Gelderblom, E. Rhodes and A. Druin. "Brownies or bags-of-stuff? Domain expertise in cooperative inquiry with children". In Proceedings of the 12th International Conference on Interaction Design and Children, pp. 201-210. ACM, 2013.

[16] A. Cook-Sather. "Authorizing students' perspectives: Toward trust, dialogue, and change in education". Educational researcher, vol. 31, no. 4, pp. 3-14, 2002.

[17] P. H. Christensen. "Children's participation in ethnographic research: Issues of power and representation". Children Es society, vol. 18, no. 2, pp. 165-176, 2004.

[18] S. Komulainen. "The ambiguity of the child's 'voice' in social research". Childhood, vol. 14, no. 1, pp. 11-28, 2007.

[19] M. Hill. "Children's voices on ways of having a voice: Children's and young people's perspectives on methods used in research and consultation". Childhood, vol. 13, no. 1, pp. 69-89, 2006.

[20] A. Andersson and M. Hatakka. "What are we doing?: Theories used in ICT4D research". In 12th International Conference on Social Implications of Computers in Developing Countries, pp. 282-300. 2013.

[21] B. Chimbo and H. Gelderblom. "Cross-age tutoring via social media: Motivating teenage tutors to engage in activites for the benefit of younger children". In Proceedings of the IADIS International Conference on Internet Technologies and Society. 2012. 